\title{
Survival into Adulthood of a Patient with Un-operated Single Ventricle without Pulmonary Stenosis: A Case Report
}

\author{
Kawtar Afrikh*, Loua Hattach, Nadia Fellat and Rokya Fellat \\ Unit of Cardiology A, Ibn Sina University Hospital, Morocco
}

Submission: July 10, 2017; Published: August 10, 2017

*Corresponding author: Kawtar Afrikh, Ibn Sina Universitary Hospital, Av Med Belarbi Elalaoui, BP 6203, Rabat-Institutes, Rabat- Morocco, Email: afrikh.kawtar@gmail.com

\begin{abstract}
A double inlet single ventricle is a congenital heart malformation in which both atria are connected to a common or dominant ventricle. It's a rare condition that accounts for about 1 to $2 \%$ of all congenital heart defects at birth. Prognosis without surgical intervention is considered to be poor, and survival into the adulthood is unusual. A non invasive cardiac imaging (like echocardiography) play major role in diagnosis, assessment of ventricular function and atrioventricular valves and detection of complications in pre and post operative period after a palliative or definitive surgery. A cardiac catheterization will usually be performed to evaluate defects, associated abnormalities and the amount of blood that is mixing. Several surgical options are available for this condition.
\end{abstract}

We report the case of a 28 years old man who has type A of Van Praagh's classification of single ventricle with transposition of great arteries. However, there was no pulmonary or aortic stenosis. We present this case to discuss what characteristics permitted his survival and to evaluate the complications associated with this anomaly. Single ventricle of left ventricular morphology, transposition of great arteries without systemic outflow obstruction and adequately functioning AV valves may have contributed to his survival.

Keywords: Double inlet single ventricle; Spulmonary hypertension; Congenital heart defect; Adulthood

\section{Introduction}

A double inlet single ventricle is a congenital heart malformation in which both atria are connected to a common or dominant ventricle. It's a rare condition that accounts for about 1 to $2 \%$ of all congenital heart defects at birth [1]. Prognosis without surgical intervention is considered to be poor, and survival into the adulthood is unusual.

It has been postulated that additional pulmonary valve stenosis is needed for prolonged survival as it restricts the development of pulmonary hypertension [2]. We, however, report the case of a 28 years old man with type A of Van Praagh's classification of single ventricle [3], which has survived with a wide open pulmonary circulation.

\section{Case Report}

We report a 28-year-old male patient recently diagnosed with a single ventricle. He has been admitted in our clinic with the complaints of dyspnea and cyanosis. Clinical examination has revealed the presence of clubbed fingers and cyanotic lips. Systemic blood pressure was $110 / 60 \mathrm{mmHg}$. An accentuated pulmonary component of the second heart sound was heard at the upper left sternal border. There was no evidence of heart failure (Figure 1). Chest X-ray has shown an increased cardiothoracic ratio with prominent pulmonary trunk. Electrocardiogram has exposed a normal sinus rhythm with left ventricular hypertrophy and an incomplete right bundle branch block.

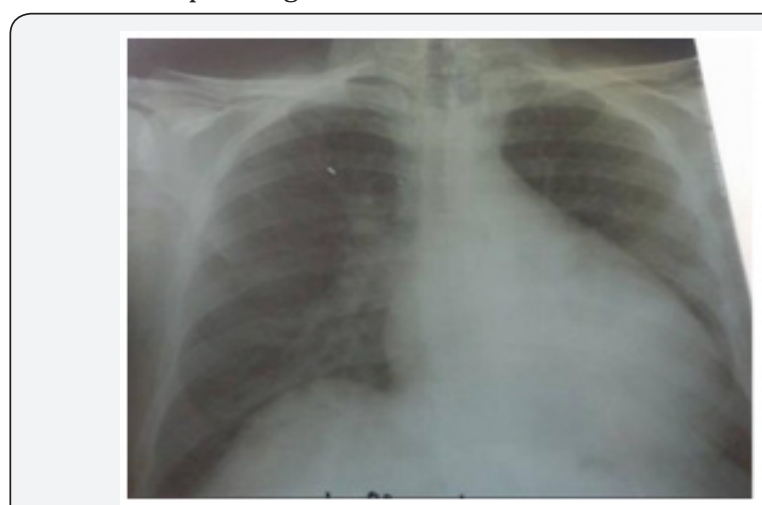

Figure 1: Postero-anterior chest X-Ray showing an increased cardiothoracic ratio with prominent pulmonary trunk. 
The Transthoracic echocardiography finding includes situs solitus of viscera and atria; two separate atrioventricular valves opening into a dominent ventricle that is morphologically a left ventricle. It communicated with the rudimentary right ventricle through the bulboventricular foramen. There was a transposition of great arteries. However, there was no pulmonary or aortic stenosis. These findings were compatible with type A of Van Praahg's classification of a single ventricle [3]. Pulmonary Hypertension was confirmed. There was normal systemic and pulmonary venous connection (Figure 2).

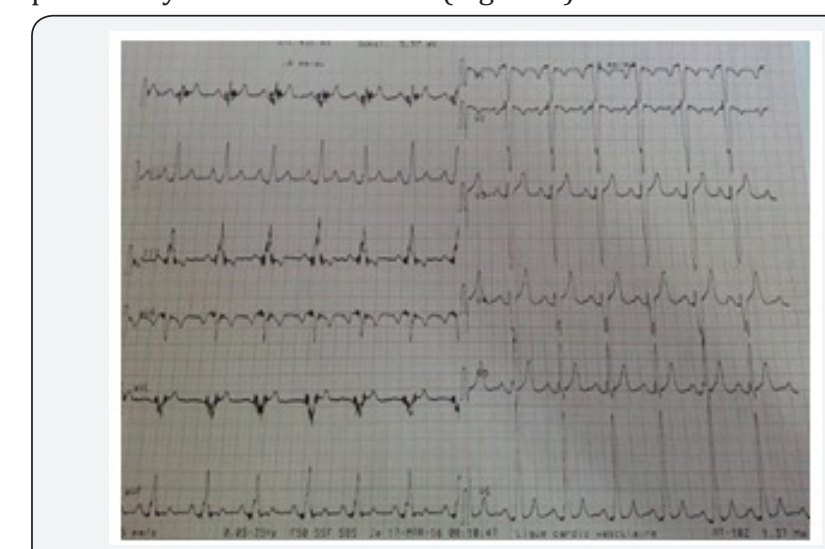

Figure 2: Electrocardiogram showing left ventricular hypertrophy and an incomplete right bundle branch block.

Cardiac catheterization has been performed. The hemodynamic results have confirmed the presence of an important pulmonary hypertension. Ventricular angiography has shown a single ventricle of left ventricular morphology with preserved systolic function, which fills two great transposed arteries.

\section{Discussion}

Single ventricle, also known as Cortriloculare biatriatum or Univentricular heart or double inlet ventricle is a rare congenital anomaly comprising $1 \%$ to $2 \%$ of all congenital heart defects in newborns [1]. Prognosis and clinical manifestations relate to pulmonary vascular resistance, degree of sub aortic stenosis but above all the importance of pulmonary stenosis. Patients with pulmonary stenosis will have cyanosis, while those with open pulmonary circulation will develop congestive heart failure secondary to pulmonary over-circulation [4].

There are three morphological types of single ventricle mentioned in literature [5,6]: Double inlet left ventricle in which the main ventricular morphology is the left type and the small outflow chamber is the right ventricle; double inlet right ventricle with a rudimentary left ventricular outflow; and the indeterminate type in which the ventricular morphology is not clear. The most common and better prognosis variety is when the ventricle is of left morphology. Another type can be mentioned, when the characteristics resemble both the ventricles with complete absence of ventricular septum [7]. With each variety, there may be situs solitus, inversus or ambiguous along with mesocardia or dextrocardia.
The single ventricle can be associated to other cardiac abnormalities, such as Atrial Septal Defect, Patent Ductus Arteriosus, anomalous systemic and pulmonary venous drainage particularly in case of situs ambiguous, and atrioventricular (AV) valve abnormalities. These latter may appear as two patent AV valves connecting to single ventricle with possibility of straddling of the left or right $\mathrm{AV}$ valve in the rudimentary chamber; there can be an atresia of right or left $\mathrm{AV}$ valve; or there may be a common AV valve [8,9]. Embryogically, defective septation of truncus arteriosus often occurs when it comes to single ventricle, leading to malposition of great arteries [10].

Trans Thoracic Echocardiography is the gold standard test in diagnosis of univentricular heart, allowing to confirm the diagnosis of the single ventricle and evaluate its systolic function, investigate as well anatomy, number and function of AV valves, position of great arteries and presence and severity of out flow obstruction (stenosis or atresia of either pulmonary or aortic valve) [11]. Echocardiographic findings in the present case have suggested the existence of a Single ventricle of left ventricular morphology, transposition of great arteries without systemic outflow obstruction, normal systemic and pulmonary venous drainage and adequately functioning AV valves. All this elements may have contributed to his survival.

A cardiac catheterization will usually be performed to evaluate defects, determine the amount of blood that is mixing, specify associated abnormalities and assess pulmonary artery pressure and pulmonary vascular resistance. Several surgical options are available, from palliative operations (especially Fontan procedure) up to heart transplantation, going through ventricular exclusion operation and separate ventricular surgery. Aortopulmonary shunt and Damus-Keye-Stansel (DKS) operation are indicated if the univentricular heart is associated to pulmonary and aortic stenosis respectively.

\section{Conclusion}

Survival into adulthood of a single ventricle is rarely reported in the literature. We however report the case of a 28 years old patient who has type A of van-pragh classification of single ventricle without pulmonary stenosis. Single ventricle of left ventricular morphology, transposition of great arteries without systemic outflow obstruction and adequately functioning $\mathrm{AV}$ valves may have contributed to his survival.

\section{References}

1. Samanek M, Voriskova M (1989) Congenital heart diseases among 815, 569 children born between 1980-1990 and their 15-year survival: a prospective Bohemia survival study. Pediatr Cardiol 10(4): 205-211.

2. Goldberg HL, Sniderman K, Devereux RB, Levin A (1983) Prolonged survival (62 years) with single ventricle. Am J Cardiol 52(1): 214-215.

3. Van Praagh R, Ongley P, Swan H (1964) Anatomic types of single or common ventricle in man: Morphological and geometric aspects of 60 necropsied cases. Am J Cardiol 13(3): 367-386.

4. Driscoll DJ (1990) Evaluation of the cyanotic newborn. Pediatr ClinNorth Am 37(1): 1-23. 
5. Anderson RH, Becker AE, Tynan M, Macartney FJ, Rigbu MZ (1984) The Univentricular atrioventricular correction: getting to the root of a thorny problem. Am J Cardiol 54(7): 822-828.

6. Ho SY, Luberbuhler JR, Anderson RH (1988) Pathology of heart with a univentricular atriovenrticular connection. In: Rosenberg HS, Bernstein J (Eds.), cardiovascular diseases. Perspectives in pediatric pathology 12: 66-69.

7. Agnihotri G, Mahajan D (2014) Cor triloculare biatriatum - A case report. Nepal Med Coll J 16(2-4): 198-200.

8. Sahn DJ, Harder JR, Freedom RM, Duncan WJ, Rowe RD, et al (1982) Cross sectional echocardiographic diagnosis and subclassification of univentricular hearts: imaging studies of atrioventricular valves septal structures and rudimentary outflow chambers. Circulation 66(5) 1070-1077.
9. Thies WR, Soto B, Diethelm E (1985) Angiographic anatomy of hearts with one ventricular chamber: the true single ventricle. Am J cardiol 55(11): 1363-1366

10. De La cruz MV, Miller BL (1968) Double inlet left ventricle. Two pathological specimens with comments on the embryology and on its relation to single ventricle. Circulation 37: 249-260.

11. Rajendra Kumar J, Mamta Kumbhare B, Rohan Reddy P, Kishore Kumar K (2013) Univentricular Heart with two separate Atrioventricular Valves: Diagnosed clinically and by Trans Thoracic Two-Dimensional Echocardiography. IOSR Journal of Dental and Medical Sciences (IOSRJDMS) 9(1): 85-90. 